\title{
Los demandantes de los documentos de archivo
}

\section{The plaintiffs of the archival documents Requerentes dos documentos de arquivo}

\author{
Luis Fernando Jaén García ${ }^{1}$ ORCID: 0000-0002-8675-0464
}

${ }^{1}$ Doctor en Documentación por la Universidad Carlos III de Madrid, España. Catedrático jubilado de la Universidad de Costa Rica. Académico de número y académico de la silla 17 «Ricardo Fernández Guardia (1867-1950)»-17A «José Luis Coto Conde (1911-2001)» de la Academia de Geografía e Historia de Costa Rica.jaen66@hotmail.com

\section{Resumen}

A lo largo de la historia de los archivos, han existido diferentes denominaciones para designar a las personas que acuden a estos centros de información. No obstante, en razón de que a la fecha no hemos localizado ningún término asociado ni fuentes de información que avalen teóricamente la denominación de los primeros peticionarios de los documentos de los archivos, hemos acuñado para tal fin la voz de demandante primigenio de los documentos. Los diversos términos relacionados con los solicitantes de los documentos en los archivos, que en la actualidad tienen un respaldo bibliográfico que los sustentan teóricamente, son los denominados «investigador», «usuario», «cliente» y lo que se conoce como parte interesada. Por lo tanto, en este artículo se analizan esas diferentes acepciones que a lo largo del tiempo han sido atribuidas a los demandantes de los documentos de los archivos. Una vez hecho dicho análisis, se llega a la conclusión de que de todos ellos el que en la actualidad tiene vigencia y goza de una amplia robustez es la locución usuario, pues así queda evidenciado, entre otras cosas, en las fuentes de información archivísticas de reciente cuño, las cuales mencionan y enfatizan en la dicción usuario para referirse al colectivo demandante de los servicios y productos archivísticos.

Palabras clave: DEMANDANTE PRIMIGENIO DE LOS ARCHIVOS; INVESTIGADOR; USUARIO; CLIENTE; PARTE INTERESADA. 


\begin{abstract}
Throughout the history of archives, there have been different names to designate the people who come to these information centers. However, due to the fact that to date we have not located any associated term, nor sources of information that theoretically support the name of the first petitioners of the archives documents, we have coined for this purpose the voice of «original plaintiff of the documents». The various terms related to the applicants of the documents in the archives, which currently have a bibliographic support that theoretically support them, are called «researcher», «user», «client» and what is known as «part interested». Therefore, this article analyzes those different meanings that over time have been attributed to the applicants of the archives documents. Once this analysis has been done, the conclusion is reached that of all of them the one that is currently valid and has a wide robustness is the phrase «user», as this is evidenced, among other things, in the archival information sources recently minted, which mention and emphasize in the diction «user» to refer to the group demanding archival services and products.
\end{abstract}

Keywords: PRIMAL APPLICANT OF ARCHIVES; RESEARCHER; USER; CLIENT; INTERESTED PART.

\title{
Resumo
}

Ao longo da historia dos arquivos, tem existido diferentes denominações para designar as pessoas que visitam estes centros. Embora, devido a que até o momento não temos localizado nenhum termo associado, nem fontes de informação que apoiem teoricamente, a denominação dos primeiros peticionários dos documentos do arquivo, nós criamos com este propósito, a voz de «requerente primordial dos documentos». Os diversos termos relacionados com os requerentes dos documentos nos arquivos, que na atualidade tem um apoio bibliográfico que os sustentam teoricamente, são os denominados como «investigador», «usuário», «cliente» e o que se conhece como «parte interessada». Portanto, este artigo analisa-se as diferentes acepções que ao longo do tempo foram atribuídos a os requerentes dos documentos dos arquivos. Uma vez feito este análise, chega-se a conclusão que de todos eles o que na atualidade tem vigência e tem de uma ampla robustez é a locução «usuário», pois assim fica evidenciado, entre outras coisas, nas fontes de informação arquivistica de recente cunho, as quais mencionam e enfatizam na dicção «usuário» para referir-se ao coletivo requerente dos serviços e produtos arquivisticos.

Palavras-chave: REQUERENTE PRIMORDIAL DOS DOCUMENTOS; INVESTIGADOR; USUÁRIO; CLIENTE; PARTE INTERESSADA.

Fecha de recibido: 18/02/2021

Fecha de aceptado: 01/07/2021 


\section{Introducción}

El artículo centra su atención en el análisis de las diferentes denominaciones que, a lo largo del tiempo, se han atribuido a los demandantes de los documentos de archivo. No obstante, en razón de que no existe denominación alguna para las primeras personas que históricamente iniciaron esas demandas, hemos acuñado para dicho colectivo el término demandante primigenio de los documentos.

Dentro de este orden, el estudio continúa con la primera acepción que es fundamentada en diversas fuentes bibliográficas, nos referimos a la voz investigador. Se sigue con el término usuarios, acompañado de su tipología y categorización. Sucesivamente se estudia la denominación cliente y se finaliza con la expresión parte interesada.

Por la naturaleza del trabajo, el estudio corresponde a una investigación básica o teórica y, a su vez, exploratoria. La primera, porque busca aumentar el cuerpo de conocimiento teórico de la archivística, respecto a una serie de conceptos sobre los cuales es fundamental tener claridad de su significado para evitar confusiones y malas interpretaciones a la hora de realizar cualquier investigación que tenga por finalidad a los usuarios de los archivos. La segunda tiene su fundamento en que este ha sido un tema poco estudiado por la teoría archivística general.

Debe señalarse que, en consonancia con la temática abordada, las fuentes de información que sustentan la investigación corresponden a documentos bibliográficos, tales como artículos de revistas, manuales, monografías y actas de congresos. Asimismo, dichas fuentes fueron localizadas en distintas bases de datos como, por ejemplo, Ebsco, E-Libro, ProQuest y Jstor. En razón de que la bibliografía sobre el objeto de estudio es muy limitada, el criterio de la data e idiomas para su elección fue abierto; no obstante, se hace la aclaración de que en el apartado dedicado a las referencias bibliográficas, por cuestiones de espacio, solo se consignan las que fueron citadas en el artículo.

Por último, se indica que el presente texto es un avance de la investigación Estudios de usuarios de archivos: teoría y práctica que está desarrollando el autor y que forma parte de un proyecto de investigación de mayor amplitud sobre los usuarios de los archivos. 


\section{Los demandantes primigenios de los documentos}

En el cuarto milenio antes de Cristo, florece la imponente civilización sumeria que va a legar a la humanidad uno de los aportes más revolucionarios de la historia: la escritura. Entonces, los sumerios transfieren a los seres humanos los nacientes signos escritos, plasmados en tablillas de arcilla rectangulares. De hecho, esa «formidable escritura es también la primera conocida del mundo y, quizás, la aportación más iluminadora y más generosa de los antiguos mesopotámicos al desarrollo y progreso de nuestra mente» (Bottéro, 2004, p. 10).

La escritura permite asentar acontecimientos económicos, políticos, sociales y vida cotidiana en un soporte sólido y perdurable, en este caso las llamadas «tablillas de arcilla». De esta manera se fijan signos, símbolos e ideogramas que presentan los objetos y sus relaciones. Por lo tanto, la escritura se convierte en el vehículo de trasmisión del acontecer de la humanidad.

A partir de la invención de la escritura nacen los documentos, que requieren ser organizados y custodiados en determinados sitios que permitan su acceso y su conservación. Asimismo, surgen los depósitos o archivos primigenios como lugares de acopio de los documentos, pues para esa época es impensable e ilógico hablar de una sistematización teórica de los archivos. Entonces, «la escritura origina la necesidad de un repositorio o depósito, con propósitos específicos: conservar y recuperar la información» (Arévalo Jordán, 2001, p. 21).

En aquel tiempo, los primeros depósitos de documentos o archivos surgen de la necesidad de las civilizaciones antiguas por custodiar los documentos, que luego servirán para sustentar las diversas gestiones y el desarrollo de los grupos humanos de la Antigüedad. De ahí que concordamos con Arévalo Jordán cuando señala que «los archivos, considerados como de [sic] depósitos de documentos, son las instituciones más antiguas de la humanidad, relacionadas estrechamente con los gobiernos» (Arévalo Jordán, 2001, p. 155).

Los documentos custodiados en esos archivos primigenios, de una $\mathrm{u}$ otra forma, son demandados por algunos funcionarios del aparato institucional de la época; dentro de todas las posibles razones que justifican su usabilidad, prevalecen las administrativas para satisfacer las diferentes gestiones de las organizaciones del 
momento. De esta manera, surgen las primeras demandas documentales y, por ende, los iniciales solicitantes de los documentos de los archivos, por lo que podemos denominar a ese colectivo como «demandantes primigenios de los documentos». No obstante, las fuentes de información relacionadas con dicha temática son casi nulas, no existe bibliografía que permita ampliar y argumentar más al respecto; por lo tanto, es un tema carente de investigación y una línea investigativa por desarrollar.

Con el pasar del tiempo las personas que acuden a los archivos han tenido diferentes denominaciones, que responden a distintos momentos y tendencias. De ahí que de «demandantes primigenios de los documentos» se pasa a «investigador», luego a «usuario», continuando con «cliente», para finalizar con «parte interesada», tal como se analizará en las secciones siguientes.

Empero, independientemente de la denominación que reciba o haya recibido el individuo que acude a los archivos para demandar documentos, este es un ser complejo que encierra una serie de aspectos a tener en cuenta para brindarle un adecuado servicio; lo que conlleva el análisis de «aspectos psicológicos (sensaciones, estados de ánimos...), cognitivos (estructuras mentales, conocimiento base o esquema, modos de representación semántica, efectos de los niveles de información...), lingüísticos y pragmáticos, ecológicos, sociológicos, comunicativos (necesidad de información, canales y formas...)»(Pinto Molina, 1999, p. 26).

\section{Investigador}

La Revolución francesa (1789-1799) marcó un cambio exponencial en las estructuras políticas, administrativas, sociales y culturales, entre otras, de la Europa de la época, lo que da como resultado el fin del Antiguo Régimen (sistema de gobierno anterior). En consecuencia, en el plano archivístico, y siguiendo a Lorenzo Cardoso y Vivas Moreno:

Con la demolición del Antiguo Régimen un número ingente de documentos cesaron de súbito en su función primaria de garantes de prueba, materialización de privilegios, protección de jurisdicciones y aval de actuaciones, lo cual había justificado el esfuerzo de numerosas instituciones para mantener los documentos y archivos reservados y conservados (2004, p. $32)$. 
Entonces, los centros archivísticos no estuvieron exentos de las transformaciones que provocó la caída del Antiguo Régimen; una de las más significativas fue la liberación o el acceso público a los archivos, principalmente los históricos o nacionales, que eran los mejor organizados de la época. Esa situación condujo a una mayor apertura de esas unidades de información y, por ende, al surgimiento de nuevos interesados en acceder a los documentos ahí custodiados. En suma, «la apertura de los archivos a la libre consulta se remonta a la época de la Revolución Francesa, al establecer que cada ciudadano podía libremente consultar los documentos que fuesen de su interés» (Pabón Valencia, 1996, p. 110).

Así las cosas, el siglo XIX se caracteriza por la liberalización o apertura de los archivos, que determina la mayor relevancia de los históricos o finales. De ahí que sus principales visitantes van a ser los historiadores y otros estudiosos del pasado, tal como lo expresa Cruz Mundet cuando sostiene que «los primeros en acercarse hasta ellos [archivos] fueron los eruditos; historiadores, paleógrafos, genealogistas, anticuarios...» (2003, p. 362).

Durante ese período, los archivos son considerados como el granero de los historiadores, como el laboratorio y el centro de información por excelencia de esos profesionales; pues tal como señala Cortés Alonso, «para los tiempos más recientes desde el siglo XIX, el "laboratorio de la Historia" al abrirse los archivos a los ciudadanos como resultado de las ideas de la Revolución y el Romanticismo» (2007, p. 311). Por lo tanto, de ahí «la importancia de los documentos como fuentes historiográficas y testimonios primarios e inalienables de la identidad nacional histórica» (Barraza Lescano, 1996, p. 43).

La apertura de los archivos y, por ende, la demanda de los documentos por parte de los historiadores para sustentar científicamente sus investigaciones conllevó que a los integrantes de ese colectivo que visitaba y hacía uso de los documentos custodiados en los archivos históricos se los denominara «investigadores».

Por mucho tiempo esa designación estuvo reservada exclusivamente para los historiadores, pues era el principal o único grupo que asistía a los archivos principalmente a los históricos o nacionales - para sustentar sus pesquisas; por lo tanto, en ese contexto archivístico, el apelativo de investigador era sinónimo de historiador. Por su parte, Cruz Mundet lo conceptualiza como «categoría de 
usuario habitual de los archivos, en especial de los históricos, con capacidad para buscar y manejar los documentos de su interés» (2011, p. 220).

Dentro de este orden de ideas, durante décadas en los archivos históricos se popularizó el término investigador-historiador, que presentaba una serie de características que marcaban esa particularidad de esos usuarios, a saber:

a. Tenían como formación académica la historia.

b. Realizaban como principal finalidad estudios retrospectivos.

c. Tenían como propósito la sustentación de tesis de licenciatura, maestría o doctorado.

d. Estaban afiliados a algún centro de enseñanza superior, como docentes o como investigadores.

e. Tenían un vasto conocimiento de los archivos: su fondo documental y su organización.

Paralelamente a lo anterior, durante la época de prevalencia del concepto investigador (siglo XIX y gran parte del XX), los historiadores consideraban que los archivos y los archivistas debían estar a su servicio porque ellos eran los únicos visitantes de esas unidades de información, y pensaban que eso les daba un carácter de exclusividad. De ahí que:

en un principio todo está planteado para atender al público erudito investigador de la historia. Esto ha generado una actitud pasiva por parte de los centros, pues siempre se ha pensado que la misión del archivero es el conocimiento profundo de los fondos y el desarrollo de una tarea eminentemente heurística para abrir camino a los historiadores profesionales (Torreblanca López, 1994, p. 208).

Por otra parte, aunados a los historiadores, y en menor escala, se hacen conocedores y visitantes de los archivos los paleógrafos, los anticuarios y los genealogistas, con fines investigativos muy particulares desde cada una de sus especialidades.

En la actualidad, la denominación de investigador está en desuso; sin embargo, en menor grado, en algunos archivos históricos, y por parte de algunos archivistashistoriadores, se persiste en utilizar erróneamente el vocablo investigador para designar a los visitantes de los archivos finales. 
En razón de que, a mediados del siglo $\mathrm{XX}$, los archivos son visitados por personas de diferentes profesiones, con diversas necesidades de información y con requerimientos muy puntuales del contenido de los documentos, esa situación dio origen a una nueva denominación para designar a los que acudían a los archivos, nos referimos al término usuario.

\section{Usuario}

A partir de la segunda mitad del siglo pasado se da un giro importante respecto a las visitas a los archivos, pues los exclusivos historiadores se hacen acompañar de otras poblaciones interesadas en los documentos custodiados en los centros archivísticos. De ahí que sea más frecuente encontrar en las llamadas «salas de consulta» a peticionarios muy variopintos y pertenecientes a las diversas áreas del saber. Entonces, a juicio de Cruz Mundet, «en los años cincuenta se inició tímidamente el cambio de tendencia en cuanto a la tipología de los usuarios se refiere, una evolución que en las últimas décadas se ha confirmado de forma inequívoca» (2003, p. 364).

Por lo tanto, estudiantes, docentes, científicos y ciudadanos en general acuden a los centros archivísticos a demandar ingentes cantidades de documentos. Sobre el particular, y desde la posición de Couture y Rousseau, «sin duda las informaciones contenidas en los documentos que los componen son indispensables para el trabajo de todo historiador, pero estos últimos ahora tienen nuevos vecinos en las salas de consulta: administradores, ingenieros, arquitectos, cineastas, etc.» (1988, p. 237).

Estos distintos colectivos asisten a los archivos para accesar a diversos documentos con el fin de satisfacer sus más heterogéneas necesidades de información. Por lo tanto, la investigación histórica deja de ser la única finalidad de la visitación a los archivos y pasa a estar acompañada de otras actividades de tipo administrativo, académico, personal y de ocio.

Lo anterior conlleva el cambio de denominación de investigador a usuario, pues cada uno de los colectivos que acudían a los archivos tenía intereses y necesidades particulares. Dado que la principal misión de los archivos era la usabilidad de los 
documentos que custodiaban, se comprende la derivación del término usuario a partir del nombre uso.

Entonces, el usuario es aquella persona que tiene una necesidad específica de información; por lo tanto, asiste a los archivos para demandar documentos que le permitan satisfacer esas necesidades. Así las cosas, el Diccionario de términos archivísticos, en su cuarta acepción, lo conceptualiza como «la persona que hace uso de su derecho para tener acceso a la documentación e información, con las limitaciones determinadas por el grado de accesibilidad de los documentos» (Arévalo Jordán, 2003, p. 234).

Por su parte, el Dicionário brasileiro de terminologia arquivística anota que el usuario es la «pessoa física ou jurídica que consulta arquivos. Também chamada consulente, leitor ou pesquisador» (Arquivo Nacional, 2005, p. 169). En opinión de Cruz Mundet, en la primera acepción, indica que es la «persona que usa los fondos y los servicios de un archivo» (2011, p. 350). Por último, Heredia Herrera considera que es el «beneficiario o consumidor de los contenidos documentales, de los recursos o actividades de un Archivo» (2011, p. 188).

Ahora bien, analizando cada una de las anteriores acepciones de la voz usuario tenemos, en primera instancia, la disimilitud. En segundo lugar, esa desemejanza conlleva diferentes perspectivas sobre un término tan utilizado en el ambiente de los archivos, mas poco tratado por la teoría archivística. Por su parte, Arévalo Jordán (2003) acota un elemento importante que corresponde al acceso a la información contenida en los documentos: considera que es un derecho de cualquier Estado democrático, mas no es un privilegio o una prerrogativa. Además, cuando se refiere a las «limitaciones determinadas por el grado de accesibilidad de los documentos», hace alusión a las restricciones legales (por ejemplo, el secreto de Estado, los datos sensibles o la intimidad de las personas) que tienen los documentos para su accesibilidad.

Entonces, acceso libre y gratuito a la información pública y de interés público es una responsabilidad social de los archivos, que debe estar aparejada con el principio ético de su efectiva ejecución, pues «en la mayoría de los países democráticos existen leyes que regulan el derecho de acceso a la información 
pública, que constituye una parte fundamental de sus políticas de información» (Fernández Molina, 2000, p. 445).

Por último, podemos señalar que dicha definición es muy acertada para la época, por el énfasis que pone en el libre acceso a los documentos de archivo. Era esta una situación muy importante de esclarecer y enfatizar en ese momento, pues no todas las personas tenían claridad sobre ese derecho humano.

La definición del Dicionário brasileiro de terminologia arquivística (Arquivo Nacional, 2005) es ambigua en cuanto a la confusión que establece entre investigador y usuario, que es lo que estamos contextualizando en esta sección. Además, sugiere una serie de términos relacionados como, por ejemplo, lector, que no es aplicable a la realidad de los archivos; más bien corresponde al ámbito de los servicios de nuestras primas hermanas las bibliotecas.

Respecto a la definición que brinda Cruz Mundet ut supra consideramos que es muy genérica, sin embargo, es acertada en cuanto a la divulgación que hace del vocablo usuario. Por su parte, Heredia Herrera presenta un concepto más acorde con la realidad de los archivos, inclusive lo actualiza en relación con las tendencias de las normas de calidad, al hablar de «consumidores». Asimismo, deja claro lo que hemos señalado en párrafos anteriores, la ambivalencia entre investigador y usuario, al apuntar que:

Mientras se priorizó a los Archivos históricos, existió la tendencia a no hablar sino de investigadores o historiadores, la apertura actual de los Archivos ha determinado la ampliación del concepto de sus beneficiarios, de aquí el término usuario por más amplio (2011, p. 189).

Por lo anterior, comulgamos con Heredia Herrera en cuanto a la conceptualización del vocablo usuario para designar a las personas que hacen uso de los archivos, sean estos de gestión, centrales, intermedios o finales, pues el principio y el fin de cualquier archivo son los usuarios. Sin ellos estos centros de información no tendrían ninguna razón de ser y su existencia sería irrelevante. 


\subsection{Novísimas fuentes de información relacionadas con el vocablo usuarios}

En tiempos recientes han surgido una serie de fuentes de información archivísticas que avalan la actualidad de la voz usuarios. Dentro de este orden, tenemos el Modelo de gestión de documentos y administración de archivos (MGD) para la Red de Transparencia y Acceso a la Información (RTA). Específicamente en el apartado G04/0 «Guía de implementación operacional: Control intelectual y representación», propone cuáles son los destinatarios principales de esa guía. Al referirse a los responsables secundarios, se continúa utilizando el término usuario al señalar que:

Participación en el SGD: Son aquellas personas que forman parte de la organización y que a pesar de tener otra serie de funciones o responsabilidades primarias dentro de la misma, participan en el correcto funcionamiento del SGD como responsables secundarios. Se los conoce como usuarios internos. (Franco Espiño y Pérez Alcázar, 2014a, p. 6).

Como complemento de la guía anterior, en el módulo «Guía de implementación operacional: Servicios de archivo G08/O» del citado modelo, se conceptualiza el vocablo usuario de la siguiente manera: «Persona que utiliza un determinado servicio o producto de forma habitual para ver satisfecha algún tipo de necesidad» (Franco Espiño y Pérez Alcázar, 2014b, p.16).

Asimismo, en el apartado «Directrices: Atención a la Administración G08/D01/O», señala a la Administración, es decir, las instituciones públicas, como el principal usuario de los archivos al indicar que «es necesario ser conscientes de que un archivo... tiene como usuario principal en todo momento a la organización de la cual depende y sobre la que mantiene una vinculación de carácter archivístico, pero también orgánico» (Franco Espiño y Pérez Alcázar, 2014c, p. 16). En dicho planteamiento se argumenta que los usuarios internos son los principales demandantes de los documentos que custodian los archivos.

Otra nueva fuente de información archivística, el Modelo de gestión documental y administración de archivos: Versión 1.0 elaborado por el Archivo General de la Nación de Colombia, que tiene como finalidad «servir de referente para la implementación y desarrollo de la función archivística en las entidades y 
organizaciones del Estado colombiano» (Rangel Palencia, Camacho Vargas y Mejía Echeverry, 2018, p. 60), comulga con la acepción de usuarios para designar a las personas que acuden a los archivos, pues en el módulo 3.3 «Componente Documental», señala que «la entidad elabora, aprueba y aplica el Reglamento de archivo en el que se indican las condiciones de acceso a los documentos y servicios de archivo para los usuarios internos y externos» (Rangel et al., 2018, p. 60). Por lo tanto, aparte de la aceptación de la voz usuarios, la complementa con lo que establece la teoría archivística en cuanto a su tipología, al hablar de usuarios internos y externos.

En el año 2020 sale a luz la versión 2.0 del Modelo de gestión documental colombiano, con la finalidad de «integrar aspectos claves y establecer el nivel de respuesta en el desarrollo de la función archivística de las entidades, lo cual constituye un insumo fundamental para la formulación e implementación de la política de gestión documental en el país» (Archivo General de la Nación, 2020, p. 5).

Esta nueva versión también contempla el vocablo usuario, pues en el componente «Procesos de la gestión documental», subcomponente «Gestión y trámite: Registro y distribución de documentos (trámite)» señala que «la entidad cuenta con un gestor documental que controla todas las comunicaciones oficiales recibidas por todos los canales establecidos y notifica electrónicamente a los usuarios internos y externos además controla los tiempos del trámite generando alertas» (Archivo General de la Nación, 2020, p. 52). Entonces, desde la posición del Modelo, tiene en cuenta nuevamente la tipología de usuarios, cuando hace mención a los internos y a los externos.

Como complemento de lo anterior, en el componente «Cultural», subcomponente «Participación ciudadana: Mecanismo de difusión»se indica que «la entidad implementa mecanismos para divulgar los asuntos y temáticas contenidos en sus documentos y archivos en aras de persuadir a los usuarios y a la comunidad a hacer uso de ello» (Archivo General de la Nación, 2020, p. 97). Asimismo, en el componente «Cultural», subcomponente «Participación ciudadana: Acceso y consulta de la información» apunta que: 
La entidad realiza procesos de mejora continua a las estrategias de acceso y consulta de la información contenida en sus documentos de archivo orientadas a la actualización de los instrumentos y a los procesos de innovación que faciliten el acercamiento con el usuario (Archivo General de la Nación, 2020, p. 95).

En 2020 la Unidad de Acceso a la Información Pública de Uruguay publicó la "Guía técnico-metodológica de gestión documental y administración de archivos", basada en el Modelo de Gestión Documental elaborado para la Red de Transparencia y Acceso a la Información, que tiene como propósito coadyuvar en la efectiva aplicación de la Ley de Acceso a la Información Pública de ese país. Por lo tanto, la finalidad de la guía es “... proporcionar criterios para poder mantener eficazmente el control intelectual y disponer de unas representaciones adecuadas de los documentos conservados en los archivos con las que se pueda desarrollar una gestión eficaz de la información contenida en sus fondos documentales" (Unidad de Acceso a la Información Pública, 2020, p. 17).

Para los efectos, subrayar que en el apartado de dicha guía "Contenidos de las guías de gestión documental y administración de Archivos", en el punto 4Destinatarios, se contempla a los demandantes de los documentos de los archivos bajo la denominación de la voz "usuario". Asimismo, sostiene, en concordancia con lo que establece la teoría archivística al respecto, que existen dos tipologías de destinatarios, a saber, los usuarios internos y los usuarios externos. Para el primer caso, especifica que corresponden a los jefes de unidades de gestión y el resto de personal de la institución. El segundo corresponde a los ajenos a la organización.

Siguiendo el modelo uruguayo, en el módulo 2 Evaluación documental, Compromisos, indica que "La responsabilidad del proceso de evaluación documental debe estar compartida por gestores administrativos, informáticos, archivólogos, historiadores, contadores, abogados, archiveros y usuarios". (Unidad de Acceso a la Información Pública, 2020, p. 34).

Así la cosas, en el punto 4 Servicio al archivo, se indica que "La atención a la administración es un servicio que presta una institución a usuarios internos con el objetivo de satisfacer sus necesidades mediante las actividades que desempeña" (Unidad de Acceso a la Información Pública, 2020, p. 75). Este planteamiento de la guía en cuestión, afianza la vigencia del vocablo usuario; y va más allá de eso, 
pues tiene en cuenta su tipología al indicar lo relacionado con los usuarios internos, que lo conceptualiza como “... el conjunto de unidades que componen la institución de la que el archivo forma parte como responsable de la custodia de sus documentos" (Unidad de Acceso a la Información Pública, 2020, p. 75).

Por otra parte, en 2018 surge el borrador del proyecto Ley Modelo Interamericana 2.0 sobre Acceso a la Información Pública, avalado por la Organización de Estados Americanos (OEA), que tiene como anexo la Ley Modelo Interamericana sobre Gestión Documental.

Dicho proyecto de ley responde a la Resolución de la Asamblea General de la OEA AG/RES. 2905 (XLVII-O/17) Fortalecimiento de la democracia que solicita al Departamento de Derecho Internacional que:

en consulta con los puntos focales del Programa Interamericano de Acceso a la Información Pública 1 de los Estados Miembros, y tomando en cuenta las contribuciones de la sociedad civil, identifique las áreas temáticas en las que se estima necesario la actualización o ampliación de la Ley Modelo Interamericana sobre Acceso a la Información Pública 2, y remita los resultados al Comité Jurídico Interamericano para su desarrollo (OEA, proyecto Ley Modelo Interamericana 2.0 sobre Acceso a la Información Pública, 2020, p. 1).

Así las cosas, en dicho proyecto de ley también se consigna el término usuario para designar a la persona que acude y hace uso de los documentos custodiados en los archivos, pues en la Ley Modelo Interamericana sobre Gestión Documental, artículo 14 , inciso 2 , que regula lo relacionado con el control de acceso a los documentos postula que:

los sujetos obligados establecerán los mecanismos necesarios para permitir un acceso parcial a los Documentos u ocultación de determinados datos, informando previamente al usuario de tal circunstancia, mediante el enmascaramiento de datos, la despersonalización o anonimizarían [sic], o el acceso parcial a expedientes $\mathrm{u}$ otros mecanismos similares (OEA, proyecto Ley Modelo Interamericana 2.0 sobre Acceso a la Información Pública, 2020, p. 49).

Asimismo, en el artículo 15, inciso 3, sobre las medidas mínimas de seguridad para documentación con datos personales, apunta que «las funciones y obligaciones de cada uno de los usuarios o perfiles de usuarios con acceso a datos de carácter personal y a los sistemas de información estarán claramente definidas 
y documentadas» (OEA, proyecto Ley Modelo Interamericana 2.0 sobre Acceso a la Información Pública, 2020, p. 49).

Los artículos anteriores del anexo Ley Modelo Interamericano de Gestión Documental, del proyecto Ley Modelo Interamericana 2.0 sobre Acceso a la Información Pública ponen de manifiesto la vigencia que a la fecha tiene el vocablo usuario, que se ve reforzado y ampliado en el capítulo 6, que no por casualidad se titula «Difusión y servicios de atención a los usuarios». De ahí que el artículo 24, inciso 1 dice:

El sujeto obligado desarrollará un proyecto de difusión de los Documentos en su poder, teniendo en cuenta el tipo de usuario al que se dirige, analizando las necesidades de medios y las acciones que se proponga realizar (exposiciones, visitas guiadas, publicaciones, cuentas en redes sociales, servicios educativos, etc.) (OEA, proyecto Ley Modelo Interamericana 2.0 sobre Acceso a la Información Pública, 2020, p. 53).

Por último, el artículo 26, inciso 1 señala que:

los archivos de los sujetos obligados tienen que contar con un servicio de atención al público que actúe como intermediario entre los usuarios y los Documentos y la información archivística, tanto de forma presencial como, especialmente, de forma no presencial (OEA, proyecto Ley Modelo Interamericana 2.0 sobre Acceso a la Información Pública, 2020, p. 54).

En el inciso 6 se agrega: «Las condiciones de uso del contenido de los objetos digitales del archivo disponibles en línea o de las copias obtenidas o proporcionadas deberán estar claramente definidas y manifestadas por escrito a los usuarios» (OEA, proyecto Ley Modelo Interamericana 2.0 sobre Acceso a la Información Pública, 2020, p. 54).

Aunado a lo anterior, el proyecto de ley también contempla la «Guía de aplicación de la Ley Modelo Interamericana sobre Gestión Documental». En el capítulo 4 «Acceso y seguridad de la información», punto 4.3 «Gestión de las solicitudes de acceso a documentos», inciso 2, señala que:

se proporcionará un acceso directo, sin necesidad de tramitar procedimiento alguno, a aquellos documentos de series calificadas de acceso libre tras el proceso de análisis de la accesibilidad; o a los usuarios internos o legalmente autorizados para acceder a los documentos restringidos. Todo ello, sin perjuicio de los controles de acceso y seguridad oportunos (OEA, proyecto Ley Modelo Interamericana 2.0 sobre Acceso a la Información Pública, 2020, p. 77). 
En este caso, aparte de ratificar la actualidad del concepto usuario, hace alusión a su tipología, al referirse a los usuarios internos.

Asimismo, en la citada guía, en el capítulo 6 «Difusión y servicios de atención a los usuarios», específicamente en la descripción de la buena práctica del apartado 6.2. «Atención a la Administración por los servicios de archivo», conceptualiza a los usuarios internos como el «conjunto de unidades que componen la organización de la que el archivo forma parte como responsable de la custodia de sus documentos» (OEA, proyecto Ley Modelo Interamericana 2.0 sobre Acceso a la Información Pública, 2020, p. 93). Es decir, los usuarios internos son todas aquellas personas o unidades administrativas pertenecientes a la entidad productora de los documentos.

Como complemento de la tipología de usuarios internos, en el punto 6.4 «Atención al público», también contempla a los usuarios externos y señala que el «servicio que presta una institución a usuarios externos con el objetivo de satisfacer sus necesidades mediante las actividades que desempeña» (OEA, proyecto Ley Modelo Interamericana 2.0 sobre Acceso a la Información Pública, 2020, p. 93).

Por último, el capítulo 8 «Perfiles y capacitación del personal con relación en la gestión de documentos», apartado 8.6. «Plan de formación continua», expresa que:

se considerará una buena práctica que las instituciones públicas formen a todo el personal de la institución que asuma cualquier tipo de responsabilidad en materia de gestión de documentos, así como a los usuarios, tanto internos como externos, de los servicios del archivo (OEA, proyecto Ley Modelo Interamericana 2.0 sobre Acceso a la Información Pública, 2020, p. 100).

Para finalizar el análisis de las fuentes de información archivísticas más recientes que justifican la vigencia del vocablo usuario, tenemos la Guía nacional para la publicación de datos abiertos: Versión 1, de Costa Rica, que en el apartado G «Proceso de apertura», punto1 «Identificación de la demanda con consulta a actores del ecosistema», señala: «Dialogue con los entes y las personas usuarias actuales y potenciales de los datos (ya sean ciudadanía, empresas, organizaciones no gubernamentales o desarrolladores)». Además indica como una de las 
recomendaciones de la aplicación de esta etapa que «involucre personas usuarias desde el principio del proceso y mantenga contacto con ellas» (Comisión Nacional de Datos Abiertos, 2020, p. 14). Entonces, en la citada guía, utilizando el llamado «lenguaje inclusivo», se hace referencia a los usuarios como actores principales dentro de dicho proceso. Asimismo, alude a la categorización de usuarios, en este caso, los potenciales.

Por otra parte, en el apartado 3 de la guía «Priorización de los conjuntos de datos a liberar», específicamente en la figura 7 «Criterios para facilitar la evaluación y priorización de datos», pregunta: «¿Quiénes son o podrían ser las personas usuarias internas y externas?»(Comisión Nacional de Datos Abiertos, 2020, p. 18). En este caso, es patente la correcta utilización de la teoría de la tipología de usuarios en relación con los internos y los externos.

En lo que llevamos de este siglo, han surgido nuevas denominaciones con la finalidad de homologar o sustituir el vocablo usuario, como veremos en los párrafos siguientes. No obstante, las fuentes de información archivística más reciente, específicamente las relacionadas con uno de los temas de mayor impacto y de actualidad como es la gestión documental, vienen a afianzar la prevalencia de la locución usuario, como la 'persona que acude a los archivos para satisfacer determinadas necesidades de información', tal y como se ha analizado en líneas atrás.

Habida cuenta de lo expresado anteriormente, en vez de catapultar dicha denominación, los recientes modelos y el proyecto de Ley Modelo sobre Gestión Documental y la Guía nacional para la publicación de datos abiertos de Costa Rica, reivindican la voz usuario dentro del ámbito archivístico, al acentuar y adoptar en sus postulados dicho término para designar a la persona que acude a los archivos con la finalidad de satisfacer sus variopintas necesidades de información.

En esa coyuntura, el Modelo de gestión de documentos y administración de archivos (MGD) para la Red de Transparencia y Acceso a la Información (RTA) (España); el Modelo de gestión documental y administración de archivos, versión 1.0 y versión 2.0 (Colombia); las Guías técnico-metodológicas de gestión documental y administración de archivos (Uruguay); el proyecto Ley Modelo 
Interamericana 2.0 sobre Acceso a la Información Pública y los anexos «Ley Modelo Interamericano de Gestión Documental» y la «Guía de aplicación Ley Modelo Interamericana sobre Gestión Documental»; y la Guía nacional para la publicación de datos abiertos (Costa Rica) ponen de manifiesto la prevalencia, actualidad y viabilidad de la utilización del vocablo usuario.

Culmina esta sección con la consideración de que, en la actualidad, el término usuario no está obsoleto, mucho menos en desuso, dentro de la práctica, la teoría y la metodología archivística. Por el contrario, se afianza a partir de los recientes modelos de gestión documental, disposiciones legales y guía de datos abiertos supracitadas; por lo que puede convivir en perfecta armonía con otras nuevas denominaciones, a partir de sus especificidades, que hacen referencia a las personas que acuden a los archivos y hacen uso de los documentos. Pues como bien lo señala Villaseñor Rodríguez, «en la actualidad, el interés del usuario de información es manifiesto para los profesionales que desarrollan su actividad laboral en cualquier unidad de información» (2016, p. 340).

\subsection{Tipología de usuarios}

La tipología de usuarios de los archivos viene dada a partir de su origen o procedencia. Es decir, si son originarios de la entidad generadora de los documentos, se los denomina «usuarios internos»; los procedentes de entes no propios de la institución productora de los documentos son los llamados «usuarios externos».

Los internos son los que laboran en una entidad constituida de hecho y de derecho, es decir, los funcionarios de la institución a la que está adscrito el archivo, ya sea de gestión, central, intermedia o histórica.

Estos usuarios recurren a dichos archivos para demandar información que les permita realizar sus gestiones administrativas, así como la oportuna toma de medidas en el cumplimiento de las funciones y actividades que les han sido encomendadas. Por lo tanto, ellos requieren de los documentos archivísticos para:

a. las gestiones administrativas;

b. la toma de decisiones; 

c. la rendición de cuentas;
d. la transparencia;
e. la gobernabilidad;
f. la anticorrupción.

Algunos usuarios internos, pueden ser los siguientes:

a. secretarios;

b. oficinistas;

c. encargados de archivos de gestión;

d. profesionales relacionados con la gestión documental (encargados, supervisores, coordinadores);

e. tomadores de decisiones a nivel intermedio (jefaturas);

f. tomadores de decisiones a nivel superior, a saber, direcciones o máximas autoridades institucionales, quienes, como afirma Cruz Mundet, «toman las decisiones relativas a la política, a los procedimientos y a la organización» (2003, p. 213).

La tipología de usuarios internos tiende a presentar confusión en aquellas instituciones que poseen una compleja estructura administrativa, o bien que tienen sucursales distribuidas a lo largo y ancho de un territorio nacional. Por ejemplo, una entidad posee su sede central en la capital del país y, a su vez, tiene oficinas descentralizadas en las cabeceras de provincias. En este caso, todos los demandantes de información de la sede central y de las oficinas provinciales son usuarios internos porque todos ellos son funcionarios de la misma entidad. Por lo tanto, la ubicación geográfica del organismo institucional no los hace acreedores de la tipología de usuarios externos, como algunos tienden a confundir.

Otro ejemplo lo constituye el caso de las universidades que están divididas administrativamente por escuelas, facultades, centros de investigaciones, etc. Todos los demandantes de información de la Universidad X, independientemente de la unidad administrativa a la que pertenezcan, son usuarios internos. Así las cosas, si un colaborador de la Facultad de Derecho requiere de documentos del 
archivo de la Facultad de Ingeniería, este es un usuario interno porque es un funcionario de la misma Universidad $\mathrm{X}$ a la que pertenecen ambas facultades.

La tipología de usuarios externos corresponde a aquellos que no son funcionarios de la institución en la que se ubica el archivo. Es decir, son los ciudadanos que acuden a estos centros archivísticos en búsqueda de información para los fines más diversos y, de esta manera, satisfacer sus necesidades informacionales, que pueden ser de tipo profesional, administrativa, académica, personal o de ocio. Empleando las palabras de Cruz Mundet:

Los archiveros se ven envueltos en un nuevo reto profesional, consistente en adoptar todas las medidas necesarias para satisfacer las necesidades de los usuarios externos, así como captar a sectores de población poco interesada en estos servicios e incluso desconocedores de su existencia (2003, p. 364).

Asimismo, siguiendo la misma línea acerca de los usuarios externos, Heredia Herrera apunta que «la sociedad tiene nuevas exigencias y reclama nuevos derechos: transparencia y agilidad en la Administración y acceso a la información, y son los archivos los que están implicados en esas exigencias y en esos derechos» (2007, p. 13).

Si bien es cierto que durante el tiempo en que los archivos históricos tenían mayor relevancia que los administrativos, el principal usuario externo fueron los historiadores-investigadores, la irrupción de los archivos de gestión y los centrales en la palestra de la institucionalidad pública ha permitido una mayor multiplicidad del colectivo de usuarios. De ahí que, en consonancia con lo que señala Alberch i Fugueras, «los denominados archivos administrativos han posibilitado la diversificación de los usuarios, que a menudo son ciudadanos con una formación y unos intereses muy plurales» (2003, p. 176).

En razón de la diversidad de usuarios externos que acuden a los archivos, se pueden fraccionar de la siguiente manera:

a. Investigadores: Al respecto tenemos dos grupos. El primero, el de los investigadores profesionales, que tienen una formación académica en metodología de investigación y una trayectoria consolidada en la pesquisa científica. Desde el punto de vista de Cruz Mundet, ese colectivo es un «público habitual desde hace muchos años y con capacidad suficiente para moverse entre la información, 
necesitan una instalaciones e instrumentos de descripción claros y precisos para realizar sus búsquedas» (2003, p. 368). Por lo general, la finalidad de sus trabajos es la generación de nuevo conocimiento científico, que se materializa a partir de un producto tangible como un libro, artículo de revista, ponencia de congreso u otro material bibliográfico. El segundo colectivo corresponde a los investigadores aficionados, quienes no tienen una formación como los anteriores y la finalidad de sus actuaciones investigativas son de corte genealógico o de interés particular en otras temáticas.

b. Estudiantes: Está compuesto por tres segmentos. El primero, el de los estudiantes universitarios. Entre ellos se distinguen dos agrupaciones: los que deben realizar algún trabajo de fin de curso en cualquier área del saber y requieren de los documentos de archivo para sustentar sus pesquisas y los que tienen que realizar su trabajo final de graduación para obtener el grado académico de licenciatura, maestría o doctorado. El segundo lo constituyen los estudiantes de secundaria, ya sea que vayan para realizar alguna indagación puntual o como visitantes para conocer el archivo, es decir, qué es y qué hace. El último lo forman los estudiantes de primaria; aunque en menor proporción que los anteriores, su acercamiento a los archivos está en consonancia con los programas de difusión de esos centros archivísticos, como las visitas guiadas y concertadas. En términos generales, los estudiantes como colectivo visitante a los archivos se justifican, como lo expresa Cruz Mundet, por «los enfoques pedagógicos que, en las últimas décadas, propugnan una enseñanza más experimental y el conocimiento del entorno inmediato como base para el aprendizaje de lo general» (2003, p. 365).

c. Particulares: Corresponde a la sociedad en general o sociedad civil, quienes por algún interés particular o curiosidad concurren a los archivos para tratar algún asunto en concreto, o bien, como lo hace notar Cruz Mundet:

Estos acuden a los archivos con fines informativos, relacionados con el ejercicio de sus derechos, así como científico-culturales, ya se trate de investigadores científicos, ya de simples curiosos que encuentran en ello una nueva dimensión del ocio culto, todo lo cual ha dado lugar a un nuevo aspecto de la Archivística, el estudio de usuarios (2003, p. 46).

Asimismo, desde el punto de vista de Vázquez Murillo: 
Los archiveros y los archivos, conociendo este nuevo usuario al que llamaremos sociedad civil, ha de adecuar su Política a los requerimientos de información y apertura a la consulta de toda serie documental de cualquier institución gubernamental o privada que roce o toque intereses de la comunidad, sea ésta barrial, municipal o nacional» (2004, p. 103).

\subsection{Categorización de usuarios}

Una vez definida la tipología de los usuarios de archivos, hay que tener en cuenta otro aspecto que está en estricta consonancia, nos referimos a la frecuencia con que estos acuden a los archivos. De ahí que se categorizan en usuarios reales y en usuarios potenciales.

Los usuarios reales son los que más frecuentan los archivos, son asiduos de esos centros de información. Además, son consecuentes con sus necesidades de información y conocen muy bien los archivos en todas sus dimensiones archivísticas: clasificación, ordenación y descripción, entre otras.

Los usuarios potenciales son los que necesitan de información para el desarrollo de sus actividades, pero no saben dónde recurrir a demandarla. Por lo tanto, casi nunca o esporádicamente acuden a los archivos y, cuando llegan, lo hacen con muchas dudas, pues no conocen los fondos documentales ahí custodiados y, por ende, su organización; solo saben que requieren de determinada información. Además, tienen inquietudes personales y particulares sobre asuntos explícitos, o bien curiosidad por cuestiones específicas.

Por la peculiaridad que presenta este colectivo, los usuarios potenciales requieren de una formación que los instruya en el uso de los instrumentos de acceso y del fondo documental que custodia el archivo, para tener una mayor rentabilidad en cuanto a la usabilidad de la información. Es importante señalar que los usuarios potenciales pueden evolucionar y convertirse en reales.

\section{Cliente}

El vocablo cliente procede de la teoría de la gestión de la calidad y de la administración. No obstante, a finales del siglo pasado fue introducido en el ámbito de las bibliotecas y, posteriormente, hizo un guiño en los archivos, mas no tuvo el éxito esperado. Al respecto, desde la posición de Núñez Paula el «término 
proviene de la teoría y la práctica del comercio, la administración y el mercadeo, que comienza a utilizarse en la actividad informacional y bibliotecaria en la década de los 80» (2000, p. 113).

En el ámbito comercial, el concepto de cliente lleva implícito la remuneración económica para la adquisición de un servicio o de un producto, es decir, se debe cancelar una cantidad de dinero para el consumo de cualquiera de ellos. Así lo hace notar Campos Ramírez al señalar que «el término cliente es una acepción de la literatura especializada en mercadotecnia y comercialización, implica una relación monetaria mercantil; es decir, el cliente paga por un producto o servicio» (2009, p. 57).

Ahora bien, en el campo de las ciencias de la información — la archivística forma parte de estas - se concibe al cliente como «toda persona, grupo o entidad, que recibe servicios de otra, independientemente se pague o no» (Núñez Paula, 2000, p. 113). En este caso, la conceptualización de cliente no se circunscribe únicamente a la consulta y al préstamo de los documentos de archivo; va más allá de eso, pues también conlleva la demanda de los servicios y productos archivísticos que ofertan esos centros de información.

Por lo tanto, se considera cliente a aquella persona que se abastece de los servicios y de los productos que generan los archivos, de los que la consulta y el préstamo de documentos son parte de su portafolio ofertante. A su vez, Heredia Herrera señala que «en el contexto archivístico [cliente] es cualquier unidad administrativa/entidad y cualquier ciudadano que requiera de los documentos y de la información de los recursos archivísticos y también de las actividades archivísticas (formativas, de difusión)» (2011, p. 68).

Por su parte, la norma UNE-ISO 9000-2015 conceptualiza al cliente como «persona u organización que podría recibir o que recibe un producto o un servicio destinado a esa persona u organización o requerido por ella» (Asociación Española de Normalización [AENOR], 2015b, p. 20). Dicho planteamiento está en consonancia con la argumentación expuesta sobre la contextualización de cliente de archivo, es decir, lo que marca la particularidad de este término en el ámbito de los centros archivísticos es la potencial demanda de los servicios y productos que estos ofertan. 
De esta manera, a partir de la gestión de la calidad, los clientes son más exigentes en cuando a la calidad de los servicios y de los productos que consumen. Además, tienen claro cuáles sus derechos, sus deberes y las normativas legales que regulan los servicios demandantes.

A pesar de lo anterior, el término cliente no ha tenido plena aceptación en el ámbito archivístico. Se aduce que cliente es aquel que paga por el acceso a un servicio o a un producto y que, en la mayoría de los archivos, no se paga directamente por ellos, estos son gratuitos.

En suma, en la actualidad la utilización del vocablo cliente en el ámbito de los archivos es nulo, ante la prevalencia de la voz usuario; como bien queda reflejado en la bibliografía archivística contemporánea.

\section{Parte interesada}

Es en el ámbito jurídico, específicamente en el derecho procesal y en el derecho administrativo, en los que el concepto de parte interesada ha asumido su aplicabilidad inicial o, por lo menos, es en los que ha tenido mayor incidencia, sobre todo en los asuntos legales-administrativos. Por ejemplo, cuando en un proceso judicial una persona ve lesionados sus derechos, reclama y solicita que dichos derechos se incluyan en el litigio, ya que los puede perder si no los defiende. Pongamos por segundo caso lo siguiente: luego de un accidente automovilístico en el que un vehículo era conducido por otra persona que no fuera el propietario, en el juicio se llama a comparecer como parte interesada al dueño del vehículo.

Por lo anterior, en el Diccionario del español jurídico (Muñoz Machado, 2016) se recoge la expresión parte interesada. No obstante, presenta la particularidad de que la remite a la frase interés legítimo, que en su primera acepción la define como «Condición que reúne la persona para ser parte en el proceso, consistente en tener interés personal, individual o colectivo, distinto de la situación jurídica que otros ciudadanos pueden tener respecto de la misma cuestión». Asimismo, en el segundo significado señala que es el:

interés del responsable del tratamiento o de tercero, para cuya satisfacción se otorga validez al tratamiento de datos personales sin consentimiento de su 
titular, una vez efectuada la necesaria ponderación de derechos e intereses en juego, fundamentalmente de derecho a la vida privada y a la protección de datos personales (p. 89).

De los anteriores alcances, la segunda acepción es la que más se acerca a lo consignado en esta sección, pues hace alusión al tratamiento de los datos personales, que en el contexto actual del ámbito archivístico se relaciona con los diferentes actores involucrados en la trazabilidad de las gestiones administrativas que presentan algunas series documentales, tal como analizaremos más adelante.

En tiempos más recientes, el vocablo parte interesada cobra una nueva dimensión desde el contorno de la calidad; específicamente, a partir de la norma UNE-ISO 9000-2015 Sistema de gestión de calidad. Fundamentos y vocabulario, que la contextualiza como «aquellas que generan riesgo significativo para la sostenibilidad de la organización si sus necesidades y expectativas no se cumplen» (AENOR, 2015b, p. 10). Luego, en páginas siguientes, en el apartado 3 «Términos y definiciones», específicamente en el punto 3.2 «Términos relativos a la organización», se conceptualiza como la «persona u organización que puede afectar, verse afectado o percibirse como afectada por una decisión o actividad» (AENOR, 2015b, p. 19).

Entonces, parte interesada hace alusión a todas aquellas personas, clientes, propietarios, accionistas y socios, entre otros, que son esenciales en una organización, entidad o empresa, para su óptimo funcionamiento. Por ejemplo, en una panadería, las partes interesadas pueden ser los clientes, los proveedores y los inversionistas. Cada uno de ellos constituye una parte esencial para el buen funcionamiento de la empresa, en este caso, la panadería. Así las cosas, los proveedores suministran el material para hacer el pan; los clientes compran el producto, lo que permite a los inversionistas tener utilidades para la adquisición de materiales y otros beneficios que conllevan el desarrollo sostenible del negocio.

Es así que esas partes interesadas pueden verse afectadas por las disposiciones que tome la organización o empresa; por lo tanto, es imprescindible tenerlas en cuenta para el oportuno proceso de la toma de decisiones. Consecuentemente, se deben identificar las necesidades y las expectativas de las partes interesadas para su respectiva satisfacción, pues sin ellas el negocio no tendría ninguna sostenibilidad. 
Para el caso que nos compete, la norma UNE-ISO 30300 Información y documentación. Sistema de gestión para los documentos. Fundamentos y vocabularios señala que «el éxito de las organizaciones depende en gran medida de la implementación y mantenimiento de un sistema de gestión diseñado para la mejora continua de su desempeño al tiempo que atiende las necesidades de las partes interesadas» (AENOR, 2011a, p. 5).

Asimismo, la norma UNE-ISO 30301 Información y Documentación. Sistema de gestión para los documentos. Requisitos establece que «el SGD, determina los requisitos de la gestión y las expectativas de las partes interesadas (clientes y otras partes interesadas)»(AENOR, 2011b, p. 7). De lo anterior se deduce, a partir de lo indicado en el paréntesis, que el concepto de cliente no es sinónimo de parte interesada; al contrario, el primero puede estar contemplado en el segundo.

En el apartado 9 de dicha norma, «Evaluación del desempeño de SGD», específicamente el inciso $k$, del punto 9.1 .3 señala «la satisfacción de usuario y partes interesadas»; por lo tanto, se concluye que ambos términos tampoco son sinónimos y que el primero puede ser parte del segundo. Luego, en el anexo «A (Normativo)», «Procesos y Controles - Tabla A.1, A.2, 5.2», en lo correspondiente a «Controles» indica que «Las decisiones de implementación sobre las aplicaciones de gestión de documentos deben documentarse, mantenerse y ponerse a disposición de todos los usuarios que la necesiten» (AENOR, 2011b, p. 22).

Por último, el anexo «A (Informativo)», específicamente A.1 «Fuentes de información» de la norma UNE-ISO 30302 establece una especie de clasificación, para la aplicación de dicha norma. Sobre las partes interesadas señala lo siguiente (AENOR, 2015a, p. 38):

Las partes interesadas pueden ser las siguientes:

a. empleados internos y contratados que trabajan en nombre de la organización;

b. empleados internos que tienen una función de liderazgo en la gestión de los documentos (auditorías, riesgo, legal, cumplimiento, tecnología de información); 
c. socios de negocio (colaboradores en investigación, socios comerciales);

d. accionistas, propietarios, directores;

e. proveedores de productos y servicios;

f. clientes;

g. ciudadanos, organizaciones no gubernamentales y otros grupos con un interés en la organización y en lo que hace;

h. organismos reguladores o de control de cuya acción puede ser objeto la organización;

i. gobierno y administración, que pueden ser múltiples en el caso de las organizaciones que operan en distintas jurisdicciones.

Por su parte, la norma UNE-ISO 15489-1 Información y documentación. Gestión de documentos Parte 1: «Conceptos y principios» establece la tipología de las partes interesadas siguiendo los mismos postulados establecidos para los usuarios, internos y externos, pues al referirse a la gestión documental señala que «esto requiere profesionales en gestión de documentos que comprendan y atiendan las necesidades de las partes interesadas tanto internas como externas» (UNE-ISO 15489-1, 2016, p. 5).

Así las cosas, la aplicabilidad en el contexto archivístico del concepto parte interesada se puede visualizar a partir de los actores o personas que, de una u otra forma, se ven afectadas o involucradas por las acciones plasmadas en los documentos. Estos actores pueden ser internos (funcionarios) o externos (ciudadanos y organizaciones). Por ejemplo, el presupuesto de una institución tiene como parte interesada interna a los funcionarios de esa entidad, pues ellos son los beneficiados o perjudicados con la aprobación o improbación de dicho presupuesto. En el caso de ser aprobado, ellos pueden cumplir a cabalidad con las funciones o actividades encomendadas; por el contrario, de no ser aprobado, esa situación lesionaría su efectivo desarrollo profesional e institucional al no poder ejecutar la misión para la que fueron contratados.

En cuanto a la parte interesada externa, serían los entes supervisores o contralores, en este caso, el Ministerio de Hacienda y la Contraloría General de la República. 
Asimismo, es factible adicionar a los ciudadanos como parte interesada externa porque ellos pueden verse afectados con la no ejecución del presupuesto. Además, pueden acceder a dicho presupuesto porque este es una serie documental que contiene información pública y de interés público. En suma, en este caso, los actores involucrados o partes interesadas en el acto que da origen a la serie documental Presupuesto y a su acceso son los funcionarios de la entidad, el Ministerio de Hacienda, la Contraloría General de la República y los ciudadanos.

Otro ejemplo, todo funcionario público debe tener un expediente de personal, siguiendo la normativa del procedimiento administrativo. En este caso, los actores involucrados o parte interesada son la oficina de recursos humanos, la jefatura y el funcionario público. Por la naturaleza del acto que da origen al documento y a su contenido, solo va a existir la parte interesada interna, pues la información de dicho expediente no es de interés público y, por ende, los ciudadanos como parte interesada externa no son actores involucrados en el proceso y no tienen derecho a la accesibilidad del expediente.

En suma, según lo expuesto en líneas atrás, el término parte interesada no es sinónimo de usuario ni de cliente; mas existe una relación directa entre ellos, pues los dos últimos pueden estar contenidos en el primero. De ahí que, en la actualidad, en algunos procesos archivísticos, como la gestión de documentos, se tenga presente el vocablo parte interesada. Sin embargo, no hay que perder de vista que no existe sinonimia con la voz usuario.

\section{Consideraciones finales}

A lo largo de la historia de los archivos, han existido diferentes denominaciones para designar a los colectivos que acuden a estos centros de información para demandar documentos con la finalidad de satisfacer sus fines más variopintos.

En razón de que la bibliografía especializada no recoge ningún vocablo para designar a los que acudían a los archivos primigenios en la Antigüedad, hemos acuñado para ese fin la voz demandante primigenio de los documentos.

Por su parte, el primer término que recogen los textos archivísticos sobre quienes han acudido a los archivos, especialmente a los históricos o finales, es el de 
investigador, que llegó a complementarse bajo el binomio investigadorhistoriador; de esta manera, uno u otro eran considerados como lo mismo. Por lo tanto, se habló de estos como si fueran equivalentes, a tal grado que podríamos hacer una analogía con la célebre frase de los Reyes Católicos de «Monta tanto, tanta monta, Isabel como Fernando» por «Monta tanto, tanto monta, investigador como historiador». No obstante, a pesar de la buena salud que esto registró durante los siglos XVIII, XIX y primera mitad del XX, la voz investigador quedó en desuso y fue remplazada por el vocablo usuario.

Si bien es cierto que a finales del siglo pasado surgió otra dicción, cliente, proveniente del mundo de la mercadotecnia, la calidad y la administración, esta no tuvo la aceptación esperada en el ámbito archivístico, pues su filosofía no iba acorde con la realidad de los archivos en cuanto a la prestación de sus servicios y la disposición de sus productos. Aunque en alguna bibliografía se utiliza el binomio usuario/cliente, es un error teórico-conceptual, pues cada uno de ellos apunta a planteamientos disímiles que no se pueden homologar como sinónimos.

En las primeras décadas del siglo XXI, a partir de las normas ISO, específicamente las de calidad, se pone de manifiesto una nueva expresión conocida como parte interesada, que, por error, esnobismo o carencia de un análisis profundo, han pretendido equiparar a la voz usuario. No obstante, como se analizó en la sección correspondiente, no se puede hablar de una sinonimia entre ambos términos. Por lo tanto, parte interesada no es sinónimo de usuario.

Entonces, de todos los términos analizados en este artículo para designar a las personas que acuden a los archivos a demandar documentos, concluimos que actualmente la que tiene vigencia y goza de una amplia robustez es la locución usuario, pues así queda evidenciado en las fuentes de información archivísticas de reciente cuño, que la mencionan y enfatizan para referirse al colectivo demandante de los servicios y productos archivísticos. 


\section{Referencias bibliográficas}

Alberch i Fugueras, R. (2003). Los archivos: entre la memoria histórica y la sociedad del conocimiento. Barcelona: UOC.

Archivo General de la Nación. (2020). Modelo de gestión documental y administración de archivos: Versión 2.0. Bogotá: Autor.

Arévalo Jordán, V. H. (2001). Teoría, fundamentos y práctica de la archivología. Santa Fe: E-libro.net.

Arévalo Jordán, V. H. (2003). Diccionario de términos archivísticos. Buenos Aires: Ediciones del Sur.

Arquivo Nacional. (2005). Dicionário brasileiro de terminologia arquivística. Río de Janeiro: Autor.

Asociación Española de Normalización. (2011a). UNE-ISO 30300 Información y documentación. Sistema de gestión para los documentos. Fundamentos y vocabularios. Madrid: Autor.

Asociación Española de Normalización. (2011b). UNE-ISO 30301 Información y documentación. Sistema de gestión para los documentos. Requisitos. Madrid: Autor.

Asociación Española de Normalización. (2015a). UNE-ISO 30302 Información y documentación. Sistema de gestión para los documentos. Guía de implantación. Madrid: Autor.

Asociación Española de Normalización. (2015b). UNE-ISO 9000 Sistema de gestión de calidad. Fundamentos y vocabulario. Madrid: Autor.

Asociación Española de Normalización. (2016). UNE-ISO 15489-1 Información y documentación. Gestión de documentos. Parte 1: Conceptos y principios. Madrid: Autor.

Barraza Lescano, S. (1996). Historia de los archivos. En Instituto Panamericano de Geografía e Historia (Ed.). Nuestra palabra: Textos archivísticos panamericanos (pp. 11-48). Lima: Autor.

Bottéro, J. (2004). Mesopotamia: la escritura, la razón y los dioses. Madrid: Ediciones Cátedra.

Campos Ramírez, J. (2009). Los estudios de usuarios y los archivos: una alianza estratégica. Revista Códice, 5(1), 55-65. 
Comisión Nacional de Datos Abiertos. (2020). Guía nacional para la publicación de datos abiertos. Versión 1. San José, Costa Rica: Autor.

Cortés Alonso, V. (2007). Archivos de España y América: materiales para un manual I. Madrid: Fondo de Cultura Económica.

Couture, C. y Rousseau, J. (1988). Los archivos en el siglo XX. Ciudad de México: Archivo General de la Nación.

Cruz Mundet, J. R. (1994/2003). Manual de archivística (5.a ed.). Madrid: Fundación Germán Sánchez Ruipérez.

Cruz Mundet, J. R. (2011). Diccionario de archivística. Madrid: Alianza.

Fernández Molina, J. C. (2000). Los aspectos éticos en la formación de los profesionales de la información. Memoria del $V$ Encuentro de EBIBCID. Universidad de Granada.

Franco Espiño, B. y Pérez Alcázar, R. (Coords.). (2014a). Modelo de gestión de documentos y administración de archivos (MGD) para la Red de Transparencia y Acceso a la Información (RTA). Guía de implementación operacional: Control intelectual y representación. Madrid: Subdirección de Archivos Estatales.

Franco Espiño, B. y Pérez Alcázar, R. (Coords.). (2014b). Modelo de gestión de documentos y administración de archivos (MGD) para la Red de Transparencia y Acceso a la Información (RTA). Guía de implementación operacional: Servicios de archivo. Madrid: Subdirección de Archivos Estatales.

Franco Espiño, B. y Pérez Alcázar, R. (Coords.). (2014c). Modelo de Gestión de Documentos y Administración de Archivos (MGD) para la Red de Transparencia y Acceso a la Información (RTA). Directrices: Atención a la Administración. Madrid: Subdirección de Archivos Estatales.

Heredia Herrera, A. (2007). ¿Qué es un archivo? Gijón: Trea.

Heredia Herrera, A. (2011). Lenguaje y vocabularios archivísticos: algo más que un diccionario. Sevilla: Junta de Andalucía.

Lorenzo Cadarso, P. L. y Vivas Moreno, A. (2004). Lecciones de archivística general y documentación del patrimonio histórico. Extremadura: Instituto de Ciencias de la Educación.

Muñoz Machado, S. (2016). Diccionario del español jurídico. Madrid: Real Academia Española. 
Núñez Paula, I. A. (2000). Usos y definiciones de los términos relativos a los usuarios o clientes. Revista Interamericana de Bibliotecología, 23(1-2), 107-121.

Organización de Estados Americanos. (2020). Proyecto Ley Modelo Interamericana 2.0 sobre Acceso a la Información Pública. Recuperado de

http://www.oas.org/es/sla/ddi/acceso_informacion_propuesta_ley_modelo. $\underline{\text { asp }}$

Pabón Valencia, J. E. (1996). Los servicios archivísticos. En Instituto Panamericano de Geografía e Historia (Ed.), Nuestra palabra: textos archivísticos panamericanos (pp. 110-119). Lima: Autor.

Pinto Molina, M. (1999). Los usuarios/clientes de los servicios de información desde la perspectiva de la calidad: consideraciones metodológicas. Ciencias de la Información, 30(2), 23-29.

Rangel Palencia, E., Camacho Vargas, Á. M. y Mejía Echeverry, M. (2018). Modelo de Gestión Documental y Administración de Archivos. Versión 1.0. Bogotá: Archivo General de la Nación.

Torreblanca López, A. (1994). Análisis de los nuevos usuarios. Tabula, (3), 207233.

Unidad de Acceso a la Información Pública. (2020). Guías técnico-metodológicas de gestión documental y administración de archivos. Montevideo: Autor.

Vázquez Murillo, M. (2004). Administración de documentos y archivos: planteos para el siglo XXI. Buenos Aires: Alfagrama.

Villaseñor Rodríguez, I. (2016). Los estudios de usuarios para la detención de las necesidades de información y el comportamiento informativo de los usuarios de archivos. Utilización de un modelo teórico. En J. González Cachafeiro (Ed.), 9 Jornadas archivando: Usuarios, retos y oportunidades (pp. 340-358). León: Fundación Sierra-Pambley.

\section{Notas del editor}

El presente manuscrito fue aprobado para su publicación por Mario Barité.

La corrección de estilo del presente texto fue realizada por Elena Ponte en el marco del convenio celebrado entre la FHCE (Tecnicatura Universitaria en 
Corrección de Estilo-Facultad de Humanidades y Ciencias de la Educación) y la

Facultad de Información y Comunicación (Universidad de la República)

\section{Nota de contribución autoral}

El autor declara haber realizado el 100\% de la investigación. 